\title{
Community-Based Restaurant Interventions to Promote Healthy Eating: A Systematic Review
}

\author{
Jennifer N. Valdivia Espino, BS; Natalie Guerrero, BA; Natalie Rhoads, MPH; \\ Norma-Jean Simon, MPH, MPA; Anne L. Escaron, PhD, MPH; Amy Meinen, MPH, RD; \\ F. Javier Nieto, MD, MPH, PhD; Ana P. Martinez-Donate, PhD
}

Suggested citation for this article: Valdivia Espino JN, Guerrero N, Rhoads N, Simon N, Escaron AL, Meinen A, et al. Community-Based Restaurant Interventions to Promote Healthy Eating: A Systematic Review. Prev Chronic Dis 2015;12:140455. DOI: http://dx.doi.org/10.5888/pcd12.140455.

\section{PEER REVIEWED}

\section{Abstract}

\section{Introduction}

Eating in restaurants is associated with high caloric intake. This review summarizes and evaluates the evidence supporting community-based restaurant interventions.

\section{Methods}

We searched all years of PubMed and Web of Knowledge through January 2014 for original articles describing or evaluating community-based restaurant interventions to promote healthy eating. We extracted summary information and classified the interventions into 9 categories according to the strategies implemented. A scoring system was adapted to evaluate the evidence, assigning 0 to 3 points to each intervention for study design, public awareness, and effectiveness. The average values were summed and then multiplied by 1 to 3 points, according to the volume of research available for each category. These summary scores were used to determine the level of evidence (insufficient, sufficient, or strong) supporting the effectiveness of each category.

\section{Results}

This review included 27 interventions described in 25 studies published since 1979. Most interventions took place in exclusively urban areas of the United States, either in the West or the South. The most common intervention categories were the use of point- of-purchase information with promotion and communication $(\mathrm{n}=$ 6 ), and point-of-purchase information with increased availability of healthy choices $(n=6)$. Only the latter category had sufficient evidence. The remaining 8 categories had insufficient evidence because of interventions showing no, minimal, or mixed findings; limited reporting of awareness and effectiveness; low volume of research; or weak study designs. No intervention reported an average negative impact on outcomes.

\section{Conclusion}

Evidence about effective community-based strategies to promote healthy eating in restaurants is limited, especially for interventions in rural areas. To expand the evidence base, more studies should be conducted using robust study designs, standardized evaluation methods, and measures of sales, behavior, and health outcomes.

\section{Introduction}

The Social Ecological Model posits that health results from interactions between individual and environmental factors (1). The food environment, defined as access to, availability of, and affordability of food (2), changed during the last century. Increases in portion size (3), availability of fast food (4), and fast food advertising (5) contributed to greater calorie consumption. These changes, paired with a more sedentary lifestyle (6), increased snacking $(6,7)$, and more eating away from home (8) contributed to the rise in overweight and obesity rates. Since the 1970s, Americans increased their away-from-home share of calorie intake from fast food and table service restaurants, which are associated with higher caloric intake of foods high in fat and low in fiber, calcium, and iron (9). Thus, restaurants are important settings for interventions to improve the food environment. 
The purpose of this review was to inform research led by community, academic, or local public health partnerships targeting restaurants. We aim to describe previous interventions and identify the level of evidence associated with different interventions. In defining "community-based restaurant intervention," we adhere to the distinction between the community nutrition environment (encompassing the type, location, and accessibility of food outlets in a geographic community) and the organizational nutrition environment (encompassing food eaten, for example, at school or work). We focus on restaurants in the community, because access to restaurants inside organizational institutions is restricted to a subset of the public $(2,10)$. The scope of the review is also limited to nonpolicy interventions voluntarily adopted by restaurant owners, because policy implementation is a long and cumbersome process. Although policy change is important, it may not always be feasible in a short term. For that reason, we studied interventions voluntarily adopted by restaurants to improve the food environment and promote healthy eating.

\section{Methods}

\section{Data sources and study selection}

We used the following search terms to search for English-language peer-reviewed journal articles from all years of PubMed and Web of Knowledge through January 2014: restaurant intervention, fast-food intervention, dining intervention, healthy choices, healthy eating, healthful eating, healthy dining, and mindful eating. Public health professionals provided a list of authors to search with these additional terms: environment, purchase, table service, promotion, and campaign. These searches yielded an initial 770 articles. After removing duplicates, 740 articles remained. The references and cited lists of articles were examined for other relevant studies, yielding an additional 20 relevant articles.

We judged the relevance of each study on the basis of the title and abstract and then read the articles deemed relevant for our review. Articles were included if they described original research about a voluntarily adopted health promotion intervention in one or more fast food or table service restaurants in community settings (ie, not located within school or work cafeterias). A total of 27 interventions described in 25 studies published from 1979 through 2013 met the inclusion criteria and were included in the review (Figure 1).

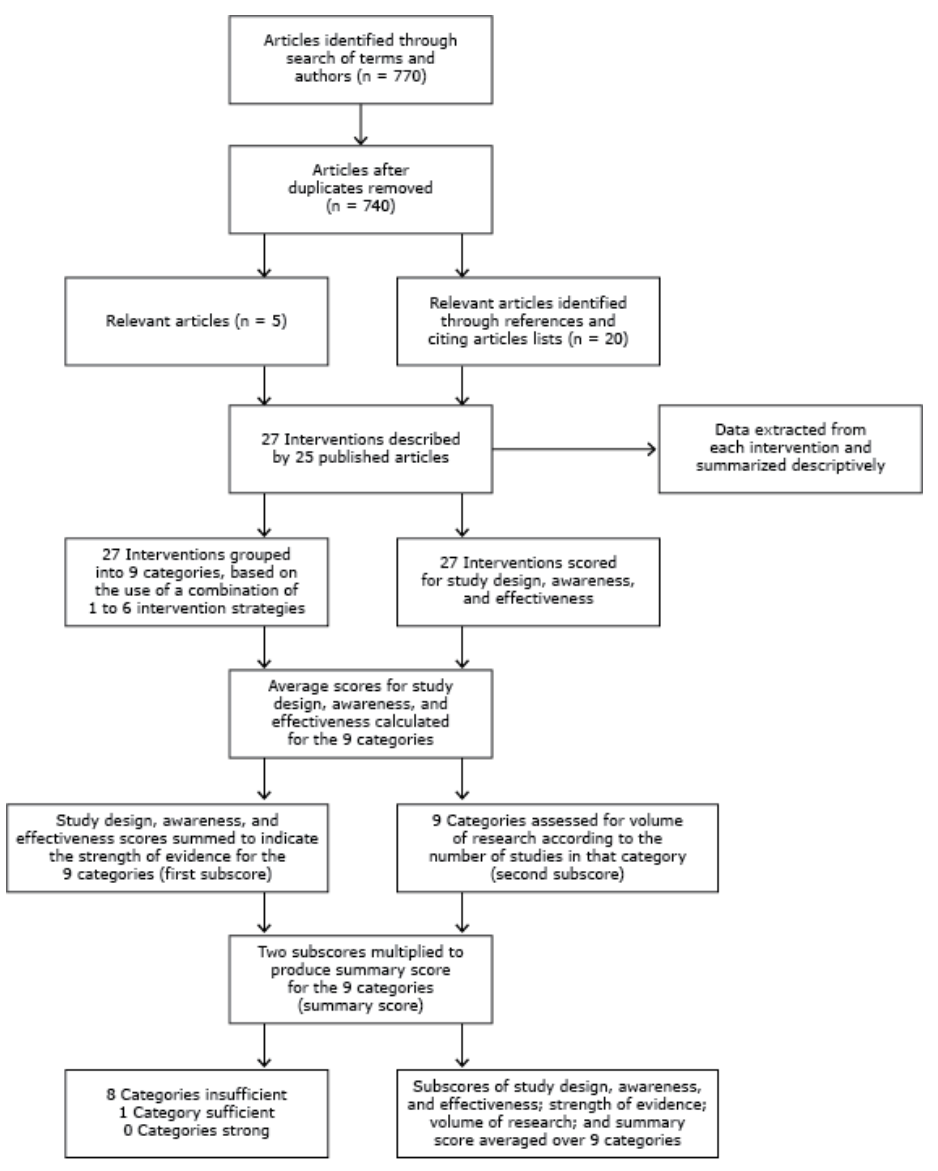

Figure 1. Methods to select studies, extract data, and describe and assess the level of evidence for community-based restaurant interventions to promote healthy eating, United States, 2014.

\section{Data extraction}

\section{Descriptions of interventions}

Previous research (11) identified 6 restaurant intervention strategies: point-of-purchase information (POP), promotion and communication (Promotion), increased availability of healthy choices (Availability), reduced prices and coupons (Pricing), catering policies (Catering), and increased access (Access). Interventions that use POP highlight healthy choices, based on nutrition criteria, on a menu, menu board, or sign. Interventions that use Promotion use banners, table tents, or advertising in print or other media to promote healthy choices. Interventions that use Availability add healthy choices to the menu or modify menu items to make them healthier. Interventions that use Pricing offer special discounts or coupons to encourage healthy food purchases. The Catering strategy requires that healthy choices be offered at catered events. Interventions that use Access make healthy choices

\footnotetext{
The opinions expressed by authors contributing to this journal do not necessarily reflect the opinions of the U.S. Department of Health and Human Services, the Public Health Service, the Centers for Disease Control and Prevention, or the authors' affiliated institutions.
} 
easier to locate or bring options to the public via food wagons (11). We grouped the interventions found during our review into intervention categories based on their use of any of the above strategies alone or in combination (eg, the category of POP + Promotion contained interventions that used both strategies together).

Two study authors (J.V.E. and N.G.) independently extracted data from each study (Table 1) and compared data to ensure consistency. Discrepancies were resolved through discussions among all the authors.

The main outcome measures reported were sales data (ie, quantitative measurement of purchases), patrons' reported behaviors (eg, customers requesting an item be prepared healthfully or reporting that the intervention affected their order), and theoretical mediators of behavior change (eg, customers' or community members' awareness, knowledge, intentions). We summarized the interventions using descriptive summary statistics.

\section{Assessment of evidence}

We adapted a scoring system previously used to evaluate food environment interventions in supermarkets (29) and constructed based in part on the Guide to Community Preventive Services methods of systematic review (30) and the RE-AIM framework (31). Using this system, we assigned points to each intervention for each of 3 characteristics: study design, awareness, and effectiveness.

The study design score ( 0 to 3 points) reflects the ability of a study design to evaluate the effectiveness of the intervention (29). Interventions of the greatest suitability, defined as those with a "concurrent comparison group and prospective measurement" (30), were given 3 points (29). Interventions of moderate suitability, defined as those with "retrospective designs or multiple pre- or post-measurements but no concurrent comparison group," (30) were given 2 points (29). Interventions of least suitability, defined as those with "single pre- and post-measurements and no concurrent comparison group or exposure and outcome measured in a single group at the same point in time," (30) were given 1 point (29). Studies that did not describe study design or surveyed only restaurant personnel were assigned 0 points.

Awareness, or penetrance, scores (0 to 3 points) indicate the percentage of individuals surveyed (eg, restaurant patrons, community residents) who took note of intervention activities. Interventions were assigned 3,2 , or 1 point if they reported 70 to $100 \%, 26 \%$ to $69 \%$, or $1 \%$ to $25 \%$ of the target audience were aware, respectively (29). Studies were assigned 0 points if awareness was $0 \%$ or if no measurement of awareness was reported.
Awareness scores replace Reach scores in the original scoring $(29,31)$, as awareness more specifically represents what the studies reported.

Effectiveness scores ( 0 to 3 points) reflect the intervention's effect on the main outcome measures of sales data, reported behaviors, or theoretical mediators (29). Interventions were assigned 3, 2, or 1 point if they reported an improvement of $70 \%$ or more, $26 \%$ to $69 \%$, or $1 \%$ to $25 \%$ in outcome measures associated with the intervention, respectively (eg, an intervention with a $50 \%$, or 1.5 fold, increase in sales of healthy items at postmeasurement compared with premeasurement was assigned 2 points). Interventions were given 0 points if there was no difference between groups or between pre- and post-measurements (29). Interventions for which there was no quantitative information about the magnitude of effectiveness were assigned 0 points.

A difference between our scoring and the original scoring system (29) is that, for each of the dimensions listed above, we assigned 0 points to studies with missing information. When a study reported data by outlet (32-36), subgroup of the population $(37,38)$, or follow-up time (26), we scored the intervention on the basis of average awareness and effectiveness. After assigning points to each intervention, average study design, public awareness, and effectiveness scores were computed for each of the categories. We then summed the average study design, public awareness, and effectiveness scores for each category to generate an indicator of the strength of evidence (first subscore), which has a possible range of 0 to 9 points, with higher scores representing stronger evidence levels (29).

Because replication is an important element of the scientific method, each category was assigned a volume of research score (second subscore, 1 to 3 points) reflecting the number of times these intervention categories have been replicated (29). Categories replicated 8 to 25 times were given 3 points; 2 to 7 times were given 2 points; only 1 study was given 1 point. The cutoffs were proportionally reduced from the original scoring because this review examined fewer studies ( 27 vs 33 ).

The summary score for each intervention category is the product of the 2 subscores (ie, strength and volume of research [Figure 1]), with a possible range of 0 to 27 . Categories with summary scores of 0 to 9,10 to 18 , or 19 to 27 points were classified as having insufficient, sufficient, or strong evidence, respectively $(29,30)$. These point cutoffs were again proportionally reduced from the original scoring because fewer studies were reviewed. To evaluate the overall level of evidence across all categories (ie, evidence for

The opinions expressed by authors contributing to this journal do not necessarily reflect the opinions of the U.S. Department of Health and Human Services, the Public Health Service, the Centers for Disease Control and Prevention, or the authors' affiliated institutions. 
all restaurant interventions included in the review), the summary scores for all intervention categories was summed and divided by the number of categories (29).

\section{Results}

\section{Description of interventions}

Of the 27 community-based restaurant interventions, $21(77.8 \%)$ took place in the United States, and among them, most were conducted in the West $(20,22,24,28,32,35,36)$ or South $(17,39-42)$ (Table 1). Most $(\mathrm{n}=23,85.2 \%)$ interventions took place in urban areas. Eight interventions (29.6\%, data not shown), described in 6 studies $(17,20,22,24,26,28)$, were explicitly guided by health promotion theories, models, or approaches. The median number of participating outlets was 7 (range: 1-222 restaurants), and the median duration of the interventions was 10 weeks (range: 1-260 weeks). The most popular intervention strategies, used alone or in combination with other strategies, were POP $(n=21,77.8 \%)$ and Promotion $(\mathrm{n}=21,77.8 \%)$, followed by Availability $(\mathrm{n}=17$, $63.0 \%)$ and Pricing $(n=6,22.2 \%)$. We found no interventions that used Catering or Access. The distribution of strategies used over time is shown in Figure 2.

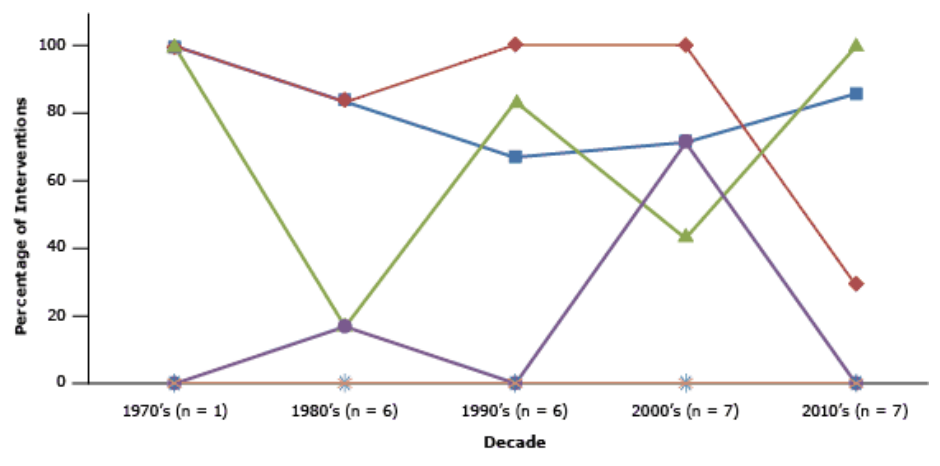

$\leftarrow$ Access $\because$ Catering $\rightarrow$ Pricing $\multimap$ Availability $\multimap$ Promotion - - POP

Figure 2. Percentage of interventions, within each decade, that implemented the following strategies: point-of-purchase information (POP), promotion and communication (Promotion), increased availability (Availability), reduced prices and coupons (Pricing), catering policies (Catering), and increased access (Access [11]). Data from 27 interventions, described in 25 reports of studies published through January 2014.

\section{Assessment of evidence}

Of the 27 interventions, $15(55 \%)$ reported improvements in at least 1 measured outcome: $6(22.2 \%)$ reported an increase of $1 \%$ to $25 \%, 6(22.2 \%)$ reported an increase of 26 to $69 \%$, and 3 $(11.1 \%)$ reported an increase of more than $70 \%$ in main outcomes. Four interventions $(14.8 \%)$ reported no change in main outcomes, and $8(29.6 \%)$ did not provide enough information to determine changes in outcomes. No intervention had an average negative impact on main outcome measures.

The 27 interventions fell within 9 categories. Table 2 shows the average scores obtained by each category. Studies included in each category are described in detail in Table 3. For all categories combined average scores were as follows: study design, 1.80 (range: 0-3); awareness, 0.60 (range: 0-1.83); effectiveness, 1.05 (range: $0-3$ ); strength of evidence, 3.45 (range: 0-6); and volume of research, 1.67 (range: 1-2). The overall summary score for all categories combined was 5.76 (range: $0-10)$. POP + Availability ( $\mathrm{n}=$ 6 ) was the only category that had sufficient evidence, based on our scoring system. This category had the highest average awareness score $($ mean $=1.83)$, moderately suitable study designs $($ mean $=$ 1.83 ), and little missing information compared with other categories. Five of the 6 interventions reported improvements up to $70 \%$ in sales data, reported behaviors, or theoretical mediators, yielding a mean effectiveness subscore of 1.33 .

The remaining 8 categories had insufficient evidence. The 6 interventions in the POP + Promotion category (summary score $=7.67$ ) had moderately suitable study designs (mean $=1.83)$, but only 3 of the 5 interventions that carried out effectiveness evaluations reported increases in main outcome measures (mean $=1.00)$. Furthermore, 4 interventions did not measure awareness, which lowered the average awareness score to 1.00. Two studies with the strongest study designs in this category had opposite findings $(17,43)$. The intervention by Horgen and Brownell included the development of a list of healthy eating options along with health messages to encourage the selection of these items. The intervention was tested over an 8-day period in 1 restaurant in Huntsville, Alabama, in 2002. The study used a strong design with premeasures and postmeasures of sales of targeted and control menu items. The results showed that sales of targeted healthy menu items during the intervention compared with baseline increased on average by $200 \%$ and that the sales of control items did not change over the intervention period (17). The other intervention, by Colby et al, promoted 3 menu items using alternating messages that focused on 1) taste and health, 2) health only, and 3) unrelated topics (control). The intervention was tested in 1 restaurant in Pawtucket, Rhode Island, over a 9-week period. By using a strong study design that compared sales of items associated with each type of message the team found no differences in sales when comparing the 2 types of health messaging with nonspecific promotion of healthy daily specials (43).

The category of Promotion + Availability $(n=3)$ had insufficient evidence (summary score $=6.67$ ). Two of the interventions $(26,37)$ showed awareness from $26 \%$ to $69 \%$ and less than a $70 \%$

\footnotetext{
The opinions expressed by authors contributing to this journal do not necessarily reflect the opinions of the U.S. Department of Health and Human Services, the Public Health Service, the Centers for Disease Control and Prevention, or the authors' affiliated institutions.
} 
improvement in main outcome measures, resulting in mean awareness and effectiveness scores of 1.33 and 1.00, respectively. However, 1 of the 3 interventions in the category provided no information about study design, awareness, or effectiveness (46). A similar pattern of limited reporting and moderate effectiveness contributed to a low score for the category POP + Availability + Promotion $(n=5$; summary score $=3.60)$. For the combination of strategies, POP + Availability + Promotion + Pricing $(n=2)$, the lack of suitable study designs and data regarding awareness and effectiveness resulted in a summary score of zero. In general, categories with 1 to 2 interventions had low scores.

\section{Discussion}

Our review of community-based restaurant interventions indicates that the level of evidence available across intervention categories is still limited. After consolidating the evidence from all categories, we found insufficient evidence to suggest that communitybased restaurant interventions were successful in promoting healthy eating. However, when examining each category of intervention, we did find some promising results based on our scoring system. For example, there was sufficient evidence to support the implementation of interventions that pair the strategies of POP + Availability. This category is represented by 6 interventions that implemented moderately strong study designs, reported public awareness, and demonstrated increases in main outcome measures.

The remaining 8 categories had insufficient evidence to suggest effectiveness according to our methods of assessment. Weak study designs and limited reporting of awareness and impact on outcomes were the main contributing factors for the low level of evidence supporting the use of these approaches. Low evidence levels for some categories were also explained by interventions that showed no or little effectiveness or interventions within the same category reporting mixed findings regarding effectiveness. Among the categories with insufficient evidence, 2, Promotion + Pricing and POP + Promotion + Pricing, showed the greatest promise. These categories included interventions with strong study designs and more than $200 \%$ improvements in measured outcomes (the highest among all studies included in this review). Despite these strengths, the categories contained only 1 or 2 interventions each, which resulted in low summary scores. These findings suggest that interventions combining these strategies may be effective and should continue to be tested in the future.

In systematically assessing the evidence, it was clear that within the same intervention category, intervention outlets, specific activities, messages, and materials varied substantially across interventions. For example, in some instances, the type of participating restaurants was not specified as fast food or family style, and not every outlet was included in the evaluation. Additionally, some activities and messages developed to promote healthy menu items may have been more effective than others. Variations in dosage and duration of the intervention also could have affected the reach and impact of the interventions.

Consequently, in interpreting the results of our review, it is important to consider not only the evidence estimated for each intervention category, but also individual interventions that have shown remarkable effects. Among these are the 3 interventions conducted by Horgen and Brownell. These interventions were tested with strong study designs and demonstrated a 2-fold to almost 4-fold increase in sales of healthy items (17). Similarly, the intervention by Papies and Veling, which used an equally strong study design, reported a 33\% difference in the proportion of healthy menu choices ordered by those in the intervention group compared with the control group (38). Three other interventions showed moderate effectiveness and outstanding levels of public awareness $(26,32,35)$.

Our review identified significant gaps in the literature. Many interventions lacked strong study designs. For example, 20 of the 27 interventions did not use comparison outlets or control menu items to evaluate the impact of the intervention on sales, patrons' reported behaviors, or theoretical mediators $(22,24,26,28,32-37,39-41,44-50)$. Of these, 8 interventions did not evaluate or did not report the magnitude of the intervention's impact on the outcomes $(22,39,40,45-47,49,50)$. Among the interventions that did report changes in outcome measures, the methods and instruments varied widely, making a comparison of effects across interventions and categories difficult. For example, some studies considered average daily sales, others measured weekly changes, and some interventions reported the number of healthy items with sales increases, but did not report the magnitude of these increases. Other studies relied on restaurant owners' qualitative interpretations of the impact of the intervention, which could not be assessed with our scoring system $(22,36,39,50)$. To expand the current evidence-base, standardized metrics must be created to evaluate restaurant interventions.

Additionally, few studies directly compared different intervention categories. The study by Horgen and Brownell was the only study that used similar methods to directly compare different intervention categories in the same restaurant (17). More comparative research of different categories of restaurant interventions needs to be conducted.

The evidence base regarding restaurant interventions would be further strengthened by more investigations outside primarily urban areas and additional data on distal outcomes. Little is known

The opinions expressed by authors contributing to this journal do not necessarily reflect the opinions of the U.S. Department of Health and Human Services, the Public Health Service, the Centers for Disease Control and Prevention, or the authors' affiliated institutions. 
about the effectiveness of these intervention strategies in urban clusters and rural areas $(26,32,40,42)$. There is also little information regarding short- or long-term health outcomes associated with these interventions. We envision these areas will be expanded as the use and study of restaurant interventions evolve in future years.

Our methods have limitations. The search for articles was limited to studies published in peer-reviewed journals. This method could have introduced publication bias if the published studies are not representative of all community-based restaurant interventions and especially if they are more likely to report successful interventions. Interventions that were successful may have been conducted in communities that were ready for behavior change and more responsive to the intervention $(27,51)$. The search was conducted through electronic databases, which may have excluded older literature available only in hard copy or not cited by articles found through the online search.

Our scoring system has limitations. In essence, we averaged the effects of different programs with a varied number of outlets, different intervention durations, distinct definitions of healthy menu items, different comparison groups, and intervention-specific instruments to measure effects. Similar to the interventions in another review (52), many interventions in this review targeted menu items according to different criteria (eg, low-fat, low-calorie) and presented POP information differently (eg, stickers, menu inserts), which may have produced different effects. Interventions with different kinds of comparison groups (eg, control restaurant, menu items, community) were considered equal in the procedure to assign point values. Similarly, interventions that produced increases in self-reported behaviors or in the theoretical mediators of healthy eating were given the same point value as those interventions that produced substantial changes in sales data, a more objective outcome. Additionally, although flexibility in implementation may have enhanced intervention adoption, this could have diluted the strength scores for specific combined strategies because the effectiveness of the strategies offered to restaurants was assessed and not necessarily those implemented by each participating outlet.

Finally, our scoring system weighs more heavily those categories that have been evaluated by a higher number of studies, highlighting the importance of replication of interventions in assessing the evidence-base. With this system, newer or innovative combinations of strategies that have only been implemented in a few published studies cannot obtain high volume of research subscores. In turn, this influences the determination of insufficient evidence. As more evaluations of those intervention categories are published in the future, the scoring can be replicated to produce updated summaries of the levels of evidence associated with healthy eating in- terventions in restaurant settings. Finally, only 1 author (J.V.E.) assigned points to each intervention and conducted the scoring analysis. This author was in touch with the creator of the original scoring system (29) and the senior corresponding author (A.M.D.) to verify correct application of the methods.

Despite these limitations, this review summarizes relevant studies and identifies future areas of research on interventions in community restaurants. Although national policy changes, such as the menu-labeling regulation (53), are important to promote healthier diets on a population level, voluntary, local changes in the food environment can also contribute to this end. To combat obesity and its related health problems, health promotion professionals must be aware of the evidence regarding these intervention strategies. We encourage investigators to continue implementing and rigorously evaluating restaurant interventions, especially those showing sufficient evidence or promising success in promoting healthy eating.

\section{Acknowledgments}

This work was supported in part by the University of Wisconsin School of Medicine and Public Health Wisconsin Partnership Program. Jennifer N. Valdivia Espino was supported by the National Institute of General Medical Sciences of the National Institutes of Health under award no. R25GM083252. The content of the publication is the sole responsibility of the authors and does not necessarily represent the official views of the University of Wisconsin or the National Institutes of Health.

\section{Author Information}

Corresponding Author: Ana P. Martinez-Donate, PhD, 610 Walnut St, 605 WARF, Madison, WI 53705, Telephone: 608-2611380. Email: martinezdona@wisc.edu.

Author Affiliations: Jennifer N. Valdivia Espino, Natalie Guerrero, Natalie Rhoads, Norma-Jean Simon, F. Javier Nieto, University of Wisconsin-Madison, Madison, Wisconsin; Anne L. Escaron, University of California, Los Angeles, California; Amy Meinen, University of Wisconsin-Madison and Wisconsin Obesity Prevention Network, Madison, Wisconsin.

\section{References}

1. Bronfenbrenner U. The ecology of human development: experiments by nature and design. Cambridge (MA): Harvard University Press; 1979.

\footnotetext{
The opinions expressed by authors contributing to this journal do not necessarily reflect the opinions of the U.S. Department of Health and Human Services, the Public Health Service, the Centers for Disease Control and Prevention, or the authors' affiliated institutions.
} 
2. Glanz K, Sallis JF, Saelens BE, Frank LD. Healthy nutrition environments: concepts and measures. Am J Health Promot 2005;19(5):330-3, ii.

3. Young LR, Nestle M. The contribution of expanding portion sizes to the US obesity epidemic. Am J Public Health 2002; 92(2):246-9.

4. Rosenheck R. Fast food consumption and increased caloric intake: a systematic review of a trajectory towards weight gain and obesity risk. Obes Rev 2008;9(6):535-47.

5. Harris JL, Pomeranz JL, Lobstein T, Brownell KD. A crisis in the marketplace: how food marketing contributes to childhood obesity and what can be done. Annu Rev Public Health 2009; 30(1):211-25.

6. Glaeser EL, Cutler DM, Shapiro JM. Why have Americans become more obese? J Econ Perspect 2003;17(3):93-118.

7. Duffey KJ, Popkin BM. Energy density, portion size, and eating occasions: contributions to increased energy intake in the United States, 1977-2006. PLoS Med 2011;8(6):e1001050.

8. Kant AK, Graubard BI. Eating out in America, 1987-2000: trends and nutritional correlates. Prev Med 2004;38(2):243-9.

9. Lin B, Guthrie JF. Nutritional quality of food prepared at home and away from home, 1977-2008. Washington (DC): United States Department of Agriculture, Economic Research Service; 2012Economic Information Bulletin No.: 142361.

10. McLeroy KR, Norton BL, Kegler MC, Burdine JN, Sumaya CV. Community-based interventions. Am J Public Health 2003;93(4):529-33.

11. Glanz K, Hoelscher D. Increasing fruit and vegetable intake by changing environments, policy and pricing: restaurant-based research, strategies, and recommendations. Prev Med 2004;39( Suppl 2):S88-93.

12. RUCA data: code definitions: version 2.0. Seattle (WA): Washington, Wyoming, Alaska, Montana, and Idaho (WWAMI) Rural Health Research Center. http:// depts.washington.edu/uwruca/ruca-codes.php. Accessed November 5, 2013.

13. Rosenstock IM. Why people use health services. Milbank Mem Fund Q 1966;44(3):94-127.

14. Rosenstock IM. Historical origins of the health belief model. Health Educ Behav 1974;2(4):328-35.

15. Baum WM, Rachlin HC. Choice as time allocation. J Exp Anal Behav 1969;12(6):861-74.

16. Rachlin H, Green L. Commitment, choice and self-control. J Exp Anal Behav 1972;17(1):15-22.

17. Horgen KB, Brownell KD. Comparison of price change and health message interventions in promoting healthy food choices. Health Psychol 2002;21(5):505-12.

18. Lefebvre RC, Flora JA. Social marketing and public health intervention. Health Educ Q 1988;15(3):299-315.
19. Ajzen I. From intentions to actions: a theory of planned behavior. In: Kuhl J, Beckmann J, editors. Action-control: from cognition to behavior, Heidelberg (DE): Springer; 1985. p. 11-39.

20. Acharya RN, Patterson PM, Hill EP, Schmitz TG, Bohm E. An evaluation of the "TrEAT Yourself Well" restaurant nutrition campaign. Health Educ Behav 2006;33(3):309-24.

21. Kretzmann JP, McKnight JL. Building communities from the inside out: a path toward finding and mobilizing a community's assets. Chicago (IL): ACTA Publications; 1993.

22. Hanni KD, Garcia E, Ellemberg C, Winkleby M. Targeting the taqueria: implementing healthy food options at Mexican American restaurants. Health Promot Pract 2009;10( 2 Suppl):91S-9S.

23. Israel BA, Schulz AJ, Parker EA, Becker AB. Review of community-based research: assessing partnership approaches to improve public health. Annu Rev Public Health 1998; 19(1):173-202.

24. Chen R, Carrillo M, Kapp J, Cheadle A, Angulo A, Chrisman $\mathrm{N}$, et al. Partnering with REACH to create a "diabetesfriendly" restaurant: a restaurant owner's experience. Prog Community Health Partnersh 2011;5(3):307-12.

25. Bandura A. Social foundations of thought and action: a social cognitive theory. Englewood Cliffs (NJ): Prentice-Hall; 1986.

26. Nothwehr FK, Snetselaar L, Dawson J, Schultz U. Promoting healthy choices in non-chain restaurants: effects of a simple cue to customers. Health Promot Pract 2013;14(1):132-8.

27. Ajzen I. The theory of planned behavior. Organ Behav Hum Decis Process 1991;50(2):179-211.

28. Sharma S, Wagle A, Sucher K, Bugwadia N. Impact of point of selection nutrition information on meal choices at a tableservice restaurant. J Foodserv Bus Res 2011;14(2):146-61.

29. Escaron AL, Meinen AM, Nitzke SA, Martinez-Donate AP. Supermarket and grocery store-based interventions to promote healthful food choices and eating practices: a systematic review. Prev Chronic Dis 2013;10:E50.

30. Briss PA, Zaza S, Pappaioanou M, Fielding J, Wright-De Agüero L, Truman BI, et al.; The Task Force on Community Preventive Services. Developing an evidence-based guide to community preventive services - methods. The Task Force on Community Preventive Services. Am J Prev Med 2000;18(1, Suppl):35-43.

31. Glasgow RE, Vogt TM, Boles SM. Evaluating the public health impact of health promotion interventions: the RE-AIM framework. Am J Public Health 1999;89(9):1322-7.

32. Albright CL, Flora JA, Fortmann SP. Restaurant menu labeling: impact of nutrition information on entree sales and patron attitudes. Health Educ Q 1990;17(2):157-67.

The opinions expressed by authors contributing to this journal do not necessarily reflect the opinions of the U.S. Department of Health and Human Services, the Public Health Service, the Centers for Disease Control and Prevention, or the authors' affiliated institutions. 
33. Richard L, O'Loughlin J, Masson P, Devost S. Healthy menu intervention in restaurants in low-income neighbourhoods: a field experience. J Nutr Educ 1999;31(1):54-9.

34. Fitzgerald CM, Kannan S, Sheldon S, Eagle KA. Effect of a promotional campaign on heart-healthy menu choices in community restaurants. J Am Diet Assoc 2004;104(3):429-32.

35. Pulos E, Leng K. Evaluation of a voluntary menu-labeling program in full-service restaurants. Am J Public Health 2010; 100(6):1035-9.

36. Nevarez CR, Lafleur MS, Schwarte LU, Rodin B, de Silva P, Samuels SE. Salud Tiene Sabor: a model for healthier restaurants in a Latino community. Am J Prev Med 2013;44(3, Suppl 3):S186-92.

37. Green KL, Steer SL, Maluk RE, Mahaffey SM, Muhajarine N. Evaluation of the Heart Smart Restaurant Program in Saskatoon and Regina, Saskatchewan. Can J Public Health 1993;84(6):399-402.

38. Papies EK, Veling H. Healthy dining. Subtle diet reminders at the point of purchase increase low-calorie food choices among both chronic and current dieters. Appetite 2013;61(1):1-7.

39. Blair AM, Drass JA, Stone M, Rhoades D, Baldwin SA, Russ KM. Restaurant challenge offers healthful meal options and builds diabetes awareness. Diabetes Educ 2011;37(4):581-8.

40. Paul PM, Novascone MA, Ganem BC, Wimme PB. "Dine to Your Heart's Content": an assessment of the program in Virginia. J Am Diet Assoc 1989;89(6):817-20.

41. Scott LW, Foreyt JP, Manis E, O’Malley MP, Gotto AMJr. A low-cholesterol menu in a steak restaurant. J Am Diet Assoc 1979;74(1):54-6.

42. Wagner JL, Winett RA. Prompting one low-fat, high-fiber selection in a fast-food restaurant. J Appl Behav Anal 1988; 21(2):179-85.

43. Colby JJ, Elder JP, Peterson G, Knisley PM, Carleton RA. Promoting the selection of healthy food through menu item description in a family-style restaurant. Am J Prev Med 1987; 3(3):171-7.

44. Forster-Coull L, Gillis D. A nutrition education program for restaurant patrons. J Nutr Educ 1988;20(1):22B-3B.

45. McPharlin RC. Dining a'la heart: offering heart-healthy restaurant dining to the public. Top Clin Nutr 1988;3(2):55-9.

46. Dwivedi G, Harvey J. Evaluation of the Heart Smart(tm) Heart Beat Restaurant Program. Can J Diet Pract Res 1999; 60(3): 159 .

47. Anderson J, Haas MH. Impact of a nutrition education program on food sales in restaurants. J Nutr Educ 1990;22(5):232-8.

48. Fitzpatrick MP, Chapman GE, Barr SI. Lower-fat menu items in restaurants satisfy customers. J Am Diet Assoc 1997; 97(5):510-4.
49. Lefebvre C. A case history of nutritional information on menus. Food Res Int 1986;4(3):153-8.

50. Economos CD, Folta SC, Goldberg J, Hudson D, Collins J, Baker Z, et al. A community-based restaurant initiative to increase availability of healthy menu options in Somerville, Massachusetts: Shape Up Somerville. Prev Chronic Dis 2009; 6(3):A102. http://www.cdc.gov/pcd/issues/2009/Jul/ 08 0165.htm Accessed Sept 20, 2013

51. Prochaska JO, DiClemente CC. Stages and processes of selfchange of smoking: toward an integrative model of change. $\mathrm{J}$ Consult Clin Psychol 1983;51(3):390-5.

52. Seymour JD, Yaroch AL, Serdula M, Blanck HM, Khan LK. Impact of nutrition environmental interventions on point-ofpurchase behavior in adults: a review. Prev Med 2004;39( Suppl 2):S108-36.

53. The Patient Protection and Affordable Care Act of 2010, Pub. L. No. 111-148, 124 Stat, 119 (March 23, 2010).

\footnotetext{
The opinions expressed by authors contributing to this journal do not necessarily reflect the opinions of the U.S. Department of Health and Human Services, the Public Health Service, the Centers for Disease Control and Prevention, or the authors' affiliated institutions.
} 


\section{Tables}

Table 1. Characteristics of 27 Community-Based Restaurant Interventions, Published Through January 2014

\begin{tabular}{|c|c|}
\hline Characteristic & $\mathrm{N}(\%)$ \\
\hline United States & $21(77.8)$ \\
\hline Canada & $5(18.5)$ \\
\hline Netherlands & $1(3.7)$ \\
\hline \multicolumn{2}{|l|}{ US region } \\
\hline South & 7 (33.3) \\
\hline Midwest & $4(19.0)$ \\
\hline West & $7(33.3)$ \\
\hline \multicolumn{2}{|l|}{ Urbanicity of intervention locations $^{a}$} \\
\hline Urban and urban cluster locations & $1(3.7)$ \\
\hline Not reported & $1(3.7)$ \\
\hline \multicolumn{2}{|c|}{ Guiding theories, models, or approaches ${ }^{b}$} \\
\hline Health belief model & $3(11.1)$ \\
\hline Matching theory & $3(11.1)$ \\
\hline
\end{tabular}

${ }^{a}$ Categories of urbanicity were urban areas (population $\left.>50,000\right)$, urban clusters $(2,500-50,000$ residents), and rural areas $(<2,500$ residents) $(12)$.

b Values represent the number of interventions that cited the specified theory, model, or approach. The cells do not sum to 27 or $100 \%$ because interventions cited multiple theories. The health belief model $(13,14)$ and matching theory $(15,16)$ were referred to in a study that produced 3 of the interventions examined (17). Social marketing (18) and the theory of reasoned action (19) were cited in a study (20). The following theories were cited once in 4 separate studies: asset-based community development $(21,22)$, community-based participatory research $(23,24)$, social cognitive theory $(25,26)$, and the theory of planned behavior $(27,28)$.

${ }^{c}$ Values represent the number of interventions that used the specified strategy. The cells do not sum to 27 or $100 \%$ because many interventions used a combination of strategies.

d Point of purchase interventions specified healthy choices on a menu, menu board, or sign (11).

e Promotion interventions use banners, table tents, or advertising to promote healthy choices (11).

${ }^{f}$ Availability interventions add healthy choices to the menu or modify menu items to make them healthier (11).

8 Pricing interventions offer discounts or coupons to encourage healthy purchases (11).

${ }^{\mathrm{h}}$ Catering interventions require healthy choices be served at catered events (11).

i Access interventions make healthy choices easier to locate (11).

j Number of restaurants participating at the time of evaluation. Median $=7$ outlets, interquartile range $(\mathrm{IQR})=1-19.5$ outlets, range $=1-222$ outlets, mean $=25.96$ outlets.

${ }^{\mathrm{k}}$ Greatest number of weeks that the intervention lasted in at least 1 restaurant. Median $=10$ weeks, IQR $=4-79$ weeks, range $=1-260$ weeks, mean $=50.27$ weeks.

I Values represent the number of interventions that measured the specified outcome. The cells do not sum to 20 or $100 \%$ because many interventions measured multiple outcomes.

$\mathrm{m}$ Quantitative measures of food purchases.

${ }^{\mathrm{n}}$ Measures of patrons requesting a menu item be prepared healthfully or consulting intervention materials in choosing meals.

'Measures of individuals' awareness, knowledge, and intentions related to the intervention or healthy eating.

${ }^{p}$ Effectiveness is an intervention's impact on the main outcome measures of sales data, reported behaviors, or theoretical mediators.

(continued on next page)

The opinions expressed by authors contributing to this journal do not necessarily reflect the opinions of the U.S. Department of Health and Human Services, the Public Health Service, the Centers for Disease Control and Prevention, or the authors' affiliated institutions. 
(continued)

Table 1. Characteristics of 27 Community-Based Restaurant Interventions, Published Through January 2014

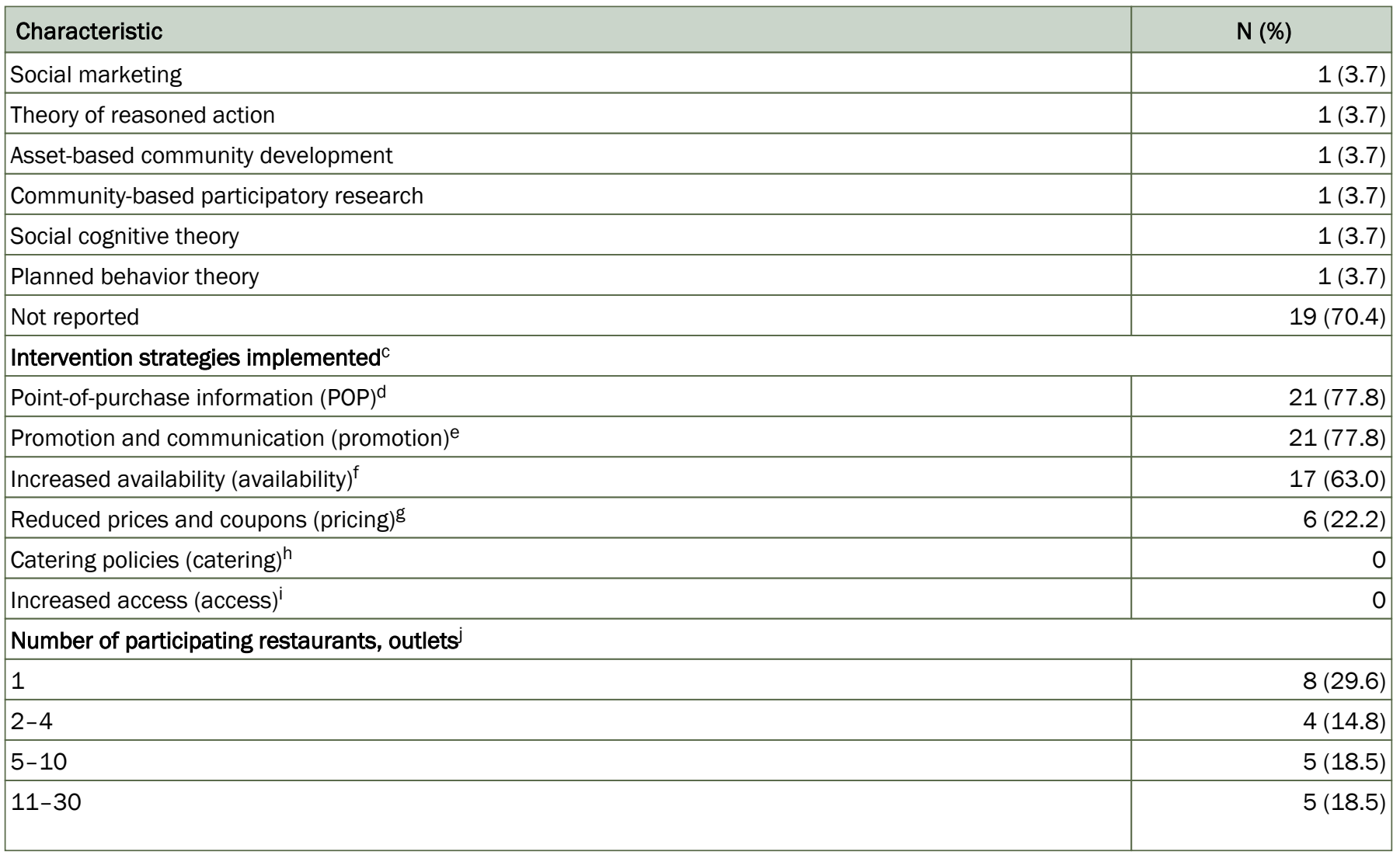

${ }^{a}$ Categories of urbanicity were urban areas (population $\left.>50,000\right)$, urban clusters (2,500-50,000 residents), and rural areas $(<2,500$ residents) $(12)$.

b Values represent the number of interventions that cited the specified theory, model, or approach. The cells do not sum to 27 or $100 \%$ because interventions cited multiple theories. The health belief model $(13,14)$ and matching theory $(15,16)$ were referred to in a study that produced 3 of the interventions examined (17). Social marketing (18) and the theory of reasoned action (19) were cited in a study (20). The following theories were cited once in 4 separate studies: asset-based community development $(21,22)$, community-based participatory research $(23,24)$, social cognitive theory $(25,26)$, and the theory of planned behavior $(27,28)$.

${ }^{c}$ Values represent the number of interventions that used the specified strategy. The cells do not sum to 27 or $100 \%$ because many interventions used a combination of strategies.

d Point of purchase interventions specified healthy choices on a menu, menu board, or sign (11).

e Promotion interventions use banners, table tents, or advertising to promote healthy choices (11).

${ }^{f}$ Availability interventions add healthy choices to the menu or modify menu items to make them healthier (11).

g Pricing interventions offer discounts or coupons to encourage healthy purchases (11).

${ }^{\mathrm{h}}$ Catering interventions require healthy choices be served at catered events (11).

i Access interventions make healthy choices easier to locate (11).

${ }^{\mathrm{j}}$ Number of restaurants participating at the time of evaluation. Median $=7$ outlets, interquartile range $(\mathrm{IQR})=1-19.5$ outlets, range $=1-222$ outlets, mean $=25.96$ outlets.

${ }^{\mathrm{k}}$ Greatest number of weeks that the intervention lasted in at least 1 restaurant. Median $=10$ weeks, IQR $=4-79$ weeks, range $=1-260$ weeks, mean $=50.27$ weeks.

' Values represent the number of interventions that measured the specified outcome. The cells do not sum to 20 or $100 \%$ because many interventions measured multiple outcomes.

${ }^{m}$ Quantitative measures of food purchases.

${ }^{n}$ Measures of patrons requesting a menu item be prepared healthfully or consulting intervention materials in choosing meals.

${ }^{\circ}$ 'Measures of individuals' awareness, knowledge, and intentions related to the intervention or healthy eating.

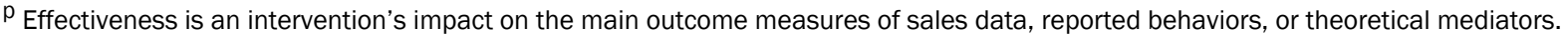


(continued)

Table 1. Characteristics of 27 Community-Based Restaurant Interventions, Published Through January 2014

\begin{tabular}{|c|c|}
\hline Characteristic & $\mathrm{N}(\%)$ \\
\hline$>30$ & $5(18.5)$ \\
\hline \multicolumn{2}{|l|}{ Duration of interventions ${ }^{k}$} \\
\hline$\leq 1$ month & $9(33.3)$ \\
\hline$>1-\leq 6$ months & $6(22.2)$ \\
\hline$>6$ months $-\leq 1$ year & $3(11.1)$ \\
\hline$>1$ year & $8(29.6)$ \\
\hline Not reported & $1(3.7)$ \\
\hline \multicolumn{2}{|l|}{ Main outcome measures' } \\
\hline Sales data ${ }^{\mathrm{m}}$ & $19(70.4)$ \\
\hline Parton's reported behaviors ${ }^{n}$ & $14(51.9)$ \\
\hline Theoretical mediators of behavior ${ }^{\circ}$ & $20(74.1)$ \\
\hline \multicolumn{2}{|l|}{ Effectiveness $^{p}$} \\
\hline Increase in outcome measures of $1 \%-25 \%$ & $6(22.2)$ \\
\hline Increase in outcome measures of $26 \%-69 \%$ & $6(22.2)$ \\
\hline Increase in outcome measures $>70 \%$ & $3(11.1)$ \\
\hline No change in outcome measures & $4(14.8)$ \\
\hline No information about magnitude of change & $8(29.6)$ \\
\hline
\end{tabular}

a Categories of urbanicity were urban areas (population $>50,000)$, urban clusters (2,500-50,000 residents), and rural areas ( $<2,500$ residents) $(12)$.

$b$ Values represent the number of interventions that cited the specified theory, model, or approach. The cells do not sum to 27 or $100 \%$ because interventions cited multiple theories. The health belief model $(13,14)$ and matching theory $(15,16)$ were referred to in a study that produced 3 of the interventions examined (17). Social marketing (18) and the theory of reasoned action (19) were cited in a study (20). The following theories were cited once in 4 separate studies: asset-based community development $(21,22)$, community-based participatory research $(23,24)$, social cognitive theory $(25,26)$, and the theory of planned behavior $(27,28)$.

${ }^{c}$ Values represent the number of interventions that used the specified strategy. The cells do not sum to 27 or $100 \%$ because many interventions used a combination of strategies.

d Point of purchase interventions specified healthy choices on a menu, menu board, or sign (11)

e Promotion interventions use banners, table tents, or advertising to promote healthy choices (11).

${ }^{f}$ Availability interventions add healthy choices to the menu or modify menu items to make them healthier (11).

$g$ Pricing interventions offer discounts or coupons to encourage healthy purchases (11).

${ }^{\mathrm{h}}$ Catering interventions require healthy choices be served at catered events (11).

i Access interventions make healthy choices easier to locate (11).

${ }^{\mathrm{j}}$ Number of restaurants participating at the time of evaluation. Median $=7$ outlets, interquartile range $(\mathrm{IQR})=1-19.5$ outlets, range $=1-222$ outlets, mean $=25.96$ outlets.

${ }^{\mathrm{k}}$ Greatest number of weeks that the intervention lasted in at least 1 restaurant. Median $=10$ weeks, IQR $=4-79$ weeks, range $=1-260$ weeks, mean $=50.27$ weeks.

' Values represent the number of interventions that measured the specified outcome. The cells do not sum to 20 or $100 \%$ because many interventions measured multiple outcomes.

$\mathrm{m}$ Quantitative measures of food purchases.

${ }^{n}$ Measures of patrons requesting a menu item be prepared healthfully or consulting intervention materials in choosing meals.

${ }^{\circ}$ Measures of individuals' awareness, knowledge, and intentions related to the intervention or healthy eating.

${ }^{p}$ Effectiveness is an intervention's impact on the main outcome measures of sales data, reported behaviors, or theoretical mediators.

The opinions expressed by authors contributing to this journal do not necessarily reflect the opinions of the U.S. Department of Health and Human Services, the Public Health Service, the Centers for Disease Control and Prevention, or the authors' affiliated institutions. 
Table 2. Average Scores for Community-Based Restaurant Interventions by Category, Published Through January 2014

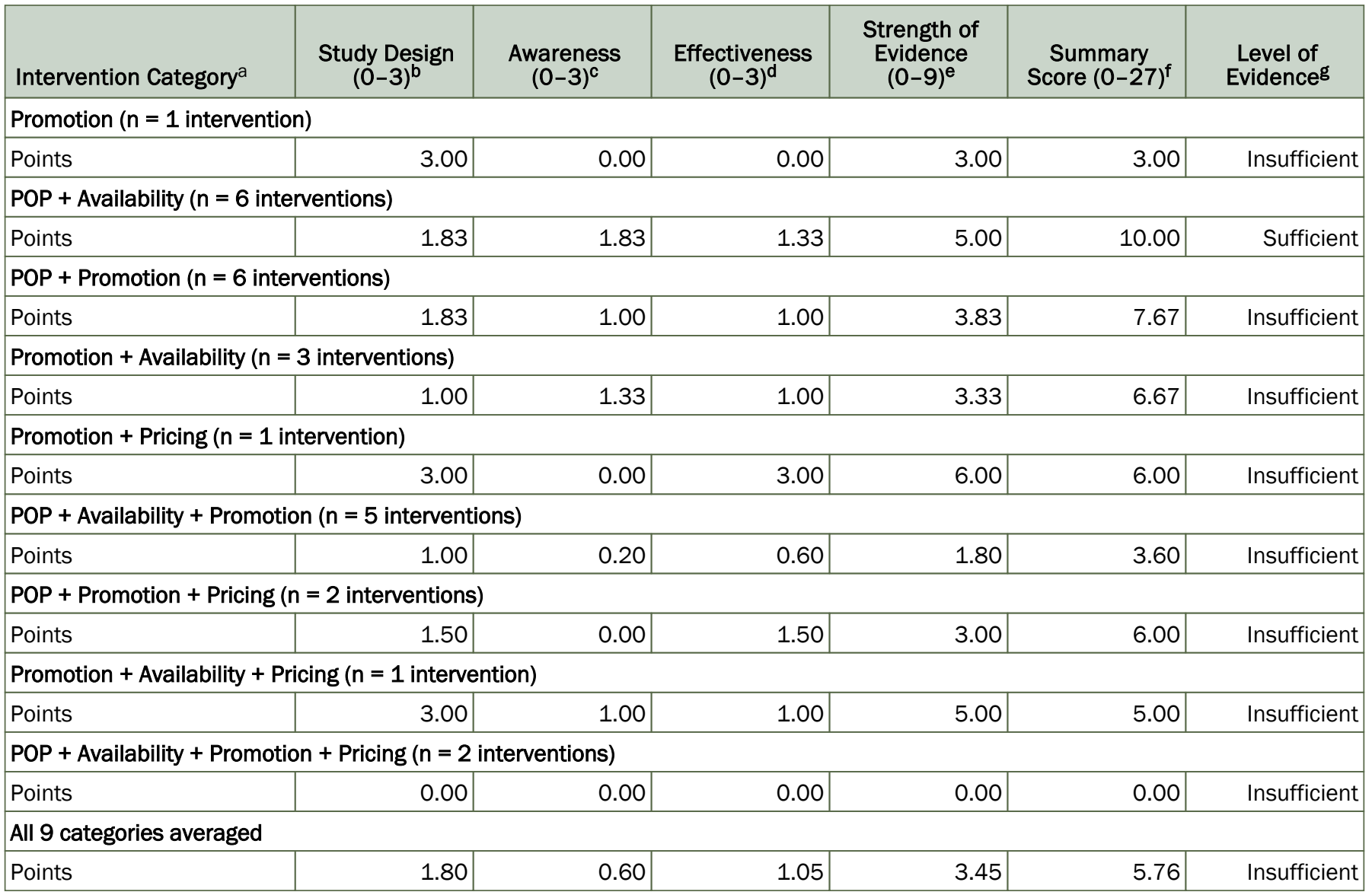

a Categories represent the use of the following 6 intervention strategies singly or combined: promotion and communication (Promotion), point-ofpurchase information (POP), increased availability (Availability), reduced prices and coupons (Pricing), catering policies (Catering), and increased access (Access [11]).

${ }^{b}$ Scored 0 to 3 points on the basis of the ability of a study design to evaluate effectiveness. Higher scores indicate stronger study design (29). Studies that did not describe the methods used to evaluate effectiveness or only surveyed restaurant owners and employees were assigned 0 points.

${ }^{\mathrm{c}}$ Scored 0 to 3 points, indicates the percentage of surveyed individuals who noticed intervention materials with higher scores indicating a greater percentage reporting awareness. Interventions were assigned 3, 2, or 1 point if they reported $70 \%$ to $100 \%, 26 \%$ to $69 \%$, or $1 \%$ to $25 \%$ of the target audience were aware, respectively (29). Studies were assigned 0 points if awareness was $0 \%$ or if no measurement of awareness was reported.

d Scored 0 to 3 points, with higher scores indicating a greater impact on intervention's main outcome measures of sales data, reported behaviors, or theoretical mediators. Interventions were assigned 3, 2, or 1 point if they reported a $\geq 70 \%, 26 \%$ to $69 \%$, or $1 \%$ to $25 \%$ improvement in outcome measures associated with the intervention (29).

e Strength of evidence score has a possible range from 0-9 and is the sum of the average study design, awareness, and effectiveness scores for each category. Higher scores indicate stronger evidence levels (29).

${ }^{\mathrm{f}}$ The summary score is the product of the strength of evidence score and the volume of evidence score. The category is assigned a volume of research score of 1-3 points according number of interventions in each category, with higher scores indicating more interventions within that category. Categories including 8 to 25 interventions were given 3 points. Categories including 2 to 7 interventions were given 2 points. Categories including only 1 intervention were given 1 point. The summary score has a possible range of 0 to 27 (29).

g Categories with scores of 0-9, 10-18, or 19-27 points have insufficient, sufficient, or strong evidence, respectively $(29,30)$.

The opinions expressed by authors contributing to this journal do not necessarily reflect the opinions of the U.S. Department of Health and Human Services, the Public Health Service, the Centers for Disease Control and Prevention, or the authors' affiliated institutions. 
Table 3. Studies Published from 1979 Through January 2014 on Community-Based Restaurant Interventions $(n=27)$ to Promote Healthy Eating, by Category

\begin{tabular}{|l|c|}
\hline $\begin{array}{l}\text { Intervention } \\
\text { Category }^{\mathrm{a}}\end{array}$ & Summary Data \\
\hline & Promotion \\
\hline
\end{tabular}

Wagner and Winett, 1988 (42)

Setting, location, and 1 intervention outlet and 1 control outlet, Blacksburg, Virginia; urban cluster urbanicity

Activities and duration Promoted eating low-fat salads with posters, table tents, banners, streamers, and computerized messages at registers; 4 weeks

\begin{tabular}{l|l} 
Study design & Prospective measurement with comparison group
\end{tabular}

Public awareness No information

Main outcome Sales data of salads and nontarget menu items

measures

Effectiveness

No significant difference between salad sales in intervention group than control group at posttest

POP + Availability

Paul et al, 1989 (40)

Setting, location, and 39 outlets, Richmond, Virginia, and Blue Ridge, Virginia; urban area and urban cluster, respectively urbanicity

Activities and duration Created and labeled American Heart Association-approved items on the menu; no duration information

Study design $\quad$ Single postmeasurement; no comparison group

Public awareness

$57 \%$ of patrons surveyed were aware of the intervention

Main outcome $\quad$ Counts of reported willingness of patrons to try specific reduced-calorie menu items and assessment of healthy measures $\quad$ eating knowledge among patrons and restaurant staff

\begin{tabular}{l|l} 
Effectiveness & Patrons surveyed were more likely to request healthy preparation of meat dishes than low-calorie desserts and
\end{tabular} entrées; no significant differences between patrons and restaurant staff in knowledge about healthy eating

Pulos and Leng, 2010 (35)

Setting, location, and 18 outlets, Pierce County, Washington; urban area urbanicity

Activities and duration Created and labeled target menu items; 2 years

Study design $\quad$ Multiple pre- and postmeasurements; no comparison group

\begin{tabular}{l|l} 
Public awareness & $71 \%$ of patrons surveyed reported noticing the nutrition information
\end{tabular}

\begin{tabular}{l|l} 
Main outcome & Reported behavioral change because of program and sales data on calories sold
\end{tabular}

measures

Effectiveness

$33 \%$ of patrons surveyed reported they changed behavior after seeing nutrition information

Chen et al, 2011 (24)

Setting, location, and 1 outlet, Seattle, Washington; urban area urbanicity

Abbreviation: POP, point of purchase.

${ }^{a}$ Interventions were grouped into categories according to their use of the following intervention strategies singly or combined: promotion and communication (Promotion), point-of-purchase information (POP), increased availability (Availability), reduced prices and coupons (Pricing), catering policies (Catering), and increased access (Access)(11).

${ }^{b}$ This intervention clearly describes that individual restaurant owners had the flexibility to choose some or all of the strategies offered. Thus, the intervention category reflects the range of activities carried out by the intervention.

(continued on next page)

The opinions expressed by authors contributing to this journal do not necessarily reflect the opinions of the U.S. Department of Health and Human Services, the Public Health Service, the Centers for Disease Control and Prevention, or the authors' affiliated institutions. 
(continued)

Table 3. Studies Published from 1979 Through January 2014 on Community-Based Restaurant Interventions ( $\mathrm{n}=27$ ) to Promote Healthy Eating, by Categorya

\begin{tabular}{|l|l|}
$\begin{array}{l}\text { Intervention } \\
\text { Category }^{\mathrm{a}}\end{array}$ & \multicolumn{1}{c}{ Summary Data } \\
\hline Activities and duration & $\begin{array}{l}\text { Educated owner about diabetes and nutrition; owner created healthy menu iten } \\
\text { options; promoted diabetes-friendly meals on menu; 6 weeks }\end{array}$ \\
\hline Study design & Multiple postmeasures, no comparison group \\
\hline Public awareness & No information \\
\hline $\begin{array}{l}\text { Main outcome } \\
\text { measures }\end{array}$ & Sales data \\
\hline Effectiveness & $11.6 \%$ of entrees sold postintervention were from the lighter options menu \\
\hline
\end{tabular}

Sharma et al, 2011 (28)

Setting, location, and 1 outlet, San Francisco Bay Area, California; urban area urbanicity

Activities and duration Created and modified menu items to meet the South Asian Heart Center and the National Cholesterol Education Program's Therapeutic Lifestyle Changes guidelines; identified healthy items with a heart symbol; 11 weeks

Public awareness $100 \%$ of a sample of adult customers noticed healthy menu items

Main outcome $\quad$ Computerized sales data

measures

Effectiveness

Sales increased by $9.9 \%$ on average; sales of 3 of the 9 target items saw increased from $38 \%$ to $75 \%$

Nevarez et al, 2013 (36)

Setting, location, and 7 outlets, South Los Angeles, California; urban area urbanicity

Activities and duration Created healthy menu items and posted calorie information on menu boards; restaurants developed brochures with detailed nutrient content; 2 years

Study design $\quad$ Single postmeasurement; no comparison group

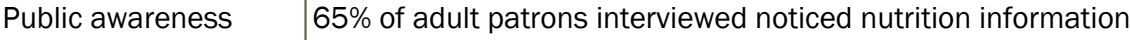

\begin{tabular}{l|l} 
Main outcome & Awareness and attitudes toward menu labeling and reported influence of the program
\end{tabular}

measures

Effectiveness

$46 \%$ of patrons interviewed reported that their purchases were influenced by calorie information

Papies and Veling, 2013 (38)

Setting, location, and 1 outlet, Netherlands; unknown urbanicity urbanicity

Activities and duration Half of the restaurant menus were supplemented with diet-related words and the other half served as control menus; 3 weeks

\begin{tabular}{l|l} 
Study design & Prospective measures with comparison group of customers with control menus
\end{tabular}

Abbreviation: POP, point of purchase.

a Interventions were grouped into categories according to their use of the following intervention strategies singly or combined: promotion and communication (Promotion), point-of-purchase information (POP), increased availability (Availability), reduced prices and coupons (Pricing), catering policies (Catering), and increased access (Access)(11).

${ }^{\mathrm{b}}$ This intervention clearly describes that individual restaurant owners had the flexibility to choose some or all of the strategies offered. Thus, the intervention category reflects the range of activities carried out by the intervention. 
(continued)

Table 3. Studies Published from 1979 Through January 2014 on Community-Based Restaurant Interventions ( $\mathrm{n}=27$ ) to Promote Healthy Eating, by Categorya

\begin{tabular}{|l|l|}
$\begin{array}{l}\text { Intervention } \\
\text { Category }\end{array}$ & \multicolumn{1}{c}{ Summary Data } \\
\hline Public awareness & No information \\
\hline $\begin{array}{l}\text { Main outcome } \\
\text { measures }\end{array}$ & Proportion of healthy menu choices ordered by intervention and control group \\
\hline Effectiveness & $\begin{array}{l}\text { The proportion of healthy menu choices was approximately 35\% in the intervention group and 15\% in the } \\
\text { control group; intervention was more effective among dieters than nondieters }\end{array}$ \\
\hline
\end{tabular}

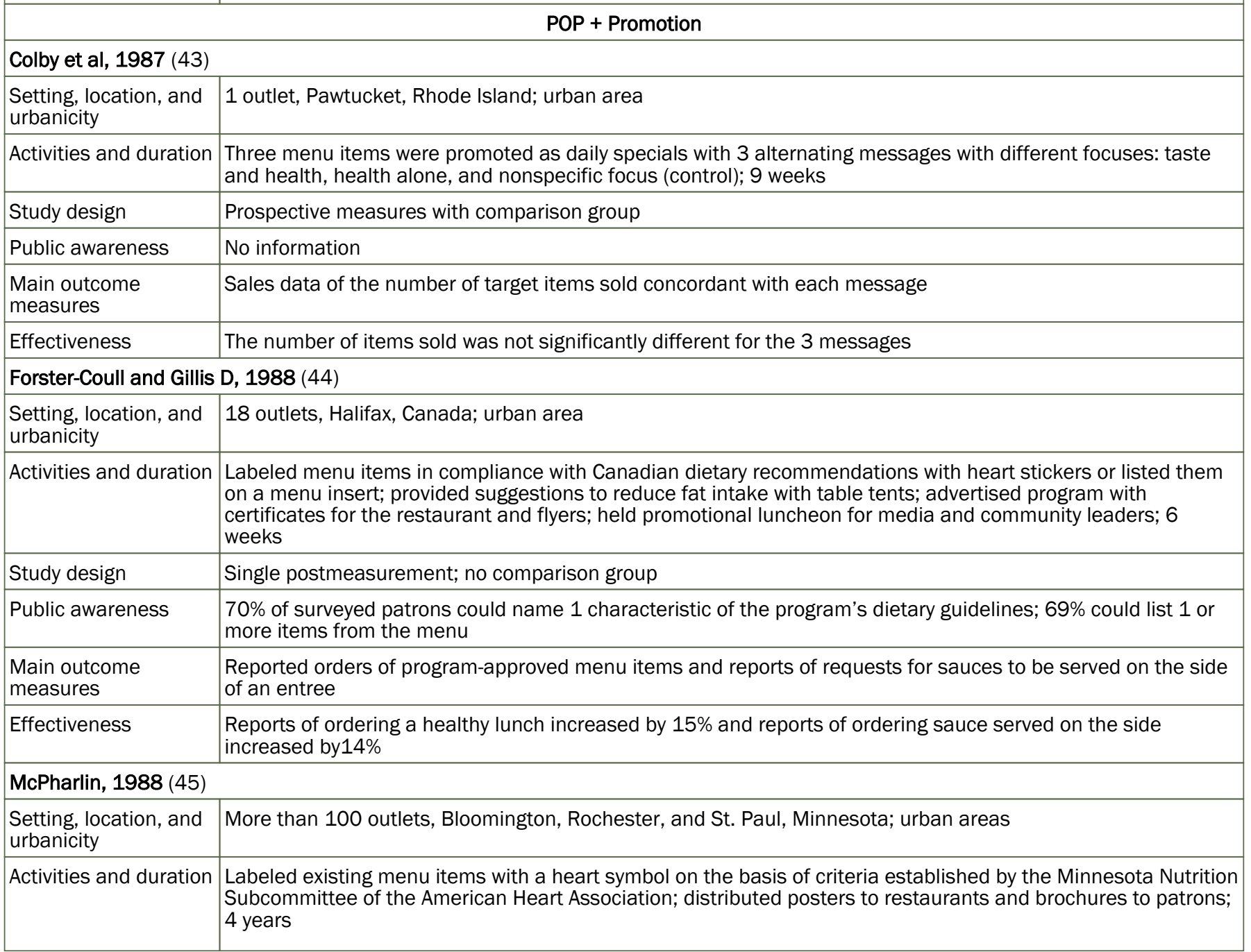

Abbreviation: POP, point of purchase.

a Interventions were grouped into categories according to their use of the following intervention strategies singly or combined: promotion and communication (Promotion), point-of-purchase information (POP), increased availability (Availability), reduced prices and coupons (Pricing), catering policies (Catering), and increased access (Access)(11).

${ }^{b}$ This intervention clearly describes that individual restaurant owners had the flexibility to choose some or all of the strategies offered. Thus, the intervention category reflects the range of activities carried out by the intervention. 
(continued)

Table 3. Studies Published from 1979 Through January 2014 on Community-Based Restaurant Interventions ( $\mathrm{n}=27$ ) to Promote Healthy Eating, by Categorya

\begin{tabular}{|l|l|}
$\begin{array}{l}\text { Intervention } \\
\text { Category }\end{array}$ & \multicolumn{1}{c}{ Summary Data } \\
\hline Study design & No information regarding design to evaluate effectiveness \\
\hline Public awareness & No information \\
\hline $\begin{array}{l}\text { Main outcome } \\
\text { measures }\end{array}$ & No information \\
\hline Effectiveness & No information \\
\hline
\end{tabular}

Albright et al, 1990 (32)

Setting, location, and 4 outlets, Northern California; urban clusters urbanicity

Activities and duration Labeled menu items low in fat and cholesterol with a heart to indicate "good for health"; encouraged patrons to create healthy meals with tip sheets of suggestions; 4 weeks

Study design $\quad$ Multiple pre- and postmeasurements; no concurrent comparison group

\begin{tabular}{l|l} 
Public awareness & $83.5 \%$ of patrons saw menu labels
\end{tabular}

Main outcome $\quad$ Sales data on target items by outlet; reported behavior change after referring to tip sheet

measures

Effectiveness $\quad$ Sales increased by an average of $15.5 \%$ with 1 outlet witnessing an increase of $40 \%$; on average, 53\% of patrons followed 1 or more tips on the tip sheet; on average, $29.5 \%$ of patrons selected a labeled item

\section{Horgen and Brownell, 2002 (17)}

Setting, location, and 1 outlet, Huntsville, Alabama; urban area urbanicity

Activities and duration Health messages (gain-framed and loss-framed) accompanied a list of healthy food options; 1 week

\begin{tabular}{l|l}
\hline Study design & Prospective measurement with a comparison group of nontarget items
\end{tabular}

Public awareness No information

\begin{tabular}{l|l} 
Main outcome & Sales data on target and nontarget items
\end{tabular}

measures

Effectiveness

Sales of target items increased by $201 \%$ on average compared with baseline; sales of nontarget comparison items remained constant

\section{Fitzgerald et al, 2004 (34)}

Setting, location, and 9 outlets, Ann Arbor, Michigan; urban area urbanicity

Activities and duration Labeled "healthy dining" menu items on the basis of program and Food and Drug Administration criteria; promoted program with newspaper advertisement, posters, and table tents; 8 weeks

Study design $\quad$ Multiple pre- and postmeasurements; no concurrent comparison group

Public awareness No information

\begin{tabular}{l|l} 
Main outcome & Electronic sales data recording the proportion of target items sold of all tracked items (a group of target and
\end{tabular}

Abbreviation: POP, point of purchase.

a Interventions were grouped into categories according to their use of the following intervention strategies singly or combined: promotion and communication (Promotion), point-of-purchase information (POP), increased availability (Availability), reduced prices and coupons (Pricing), catering policies (Catering), and increased access (Access)(11).

$\mathrm{b}$ This intervention clearly describes that individual restaurant owners had the flexibility to choose some or all of the strategies offered. Thus, the intervention category reflects the range of activities carried out by the intervention. 
(continued)

Table 3. Studies Published from 1979 Through January 2014 on Community-Based Restaurant Interventions ( $\mathrm{n}=27$ ) to Promote Healthy Eating, by Categorya

\begin{tabular}{|l|l|}
$\begin{array}{l}\text { Intervention } \\
\text { Category }\end{array}$ & \multicolumn{1}{c}{ Summary Data } \\
\hline measures & comparison items) \\
\hline Effectiveness & No significant difference in proportion of sales of target items between pre- and posttest \\
\hline
\end{tabular}

\section{Promotion + Availability}

Green KL et al, 1993 (37)

Setting, location, and 130 outlets, Saskatoon and Regina, Saskatchewan, Canada; urban areas urbanicity

Activities and duration Recruited restaurants willing to provide healthy choices or preparations upon request; promoted the program with Heart Smart logo in restaurants and advertised in the Heart and Stroke Foundation Dining Guide for community members; 1.83 years

Study design $\quad$ Single time point; no comparison group

Public awareness $\quad 22 \%$ and $41 \%$ of a sample of Regina and Saskatoon residents heard of the program; average awareness was $31.5 \%$

Main outcome $\quad$ Awareness and understanding of the program, self-reported frequency of healthy food requests, and frequency measures $\quad$ of restaurant accommodation of request

\begin{tabular}{l|l} 
Effectiveness & $6.4 \%$ and $3.6 \%$ of a sample of Regina and Saskatoon residents used the program; on average, $5 \%$ of
\end{tabular} community members made a healthy request

Dwivedi and Harvey, 1999 (46)

Setting, location, and 222 outlets, municipality of Ottawa-Carleton, Canada; urban area urbanicity

Activities and duration Recruited restaurants willing to provide healthy choices or preparations on request; encouraged patrons to request healthy preparations with menu inserts, table tents, restaurant certificates, posters, and advertisements in newspapers; 1.23 years

\begin{tabular}{l|l} 
Study design & Design not suitable to evaluate effectiveness
\end{tabular}

Public awareness $\quad$ No information

$\begin{array}{lll}\text { Main outcome } & \text { Restaurant owners' use of materials and thoughts about the program }\end{array}$

measures

Effectiveness $\quad$ No customer data

Nothwehr et al, 2013 (26)

Setting, location, and 4 outlets, small towns in lowa; rural urbanicity

Activities and duration Recruited restaurants willing to provide healthy choices or preparations on request; encouraged patrons to request healthy preparation of menu items with table tents, and window signs; 1 year

Study design $\quad$ Multiple pre- and postmeasurements; no comparison group

\begin{tabular}{l|l} 
Public awareness & Average awareness for all 3 follow-ups was $68 \%$
\end{tabular}

\begin{tabular}{l|l} 
Main outcome & Awareness and use of the program
\end{tabular}

Abbreviation: POP, point of purchase.

a Interventions were grouped into categories according to their use of the following intervention strategies singly or combined: promotion and communication (Promotion), point-of-purchase information (POP), increased availability (Availability), reduced prices and coupons (Pricing), catering policies (Catering), and increased access (Access)(11).

$\mathrm{b}$ This intervention clearly describes that individual restaurant owners had the flexibility to choose some or all of the strategies offered. Thus, the intervention category reflects the range of activities carried out by the intervention. 
(continued)

Table 3. Studies Published from 1979 Through January 2014 on Community-Based Restaurant Interventions ( $\mathrm{n}=27$ ) to Promote Healthy Eating, by Categorya

\begin{tabular}{|l|l|}
$\begin{array}{l}\text { Intervention } \\
\text { Category }^{\mathrm{a}}\end{array}$ & \multicolumn{1}{c}{ Summary Data } \\
\hline measures & \\
\hline Effectiveness & 34\% of patrons surveyed reported the table tent affected their order \\
\hline
\end{tabular}

\section{Promotion + Pricing}

Horgen and Brownell, 2002 (17)

Setting, location, and 1 outlet, Huntsville, Alabama; urban area urbanicity

Activities and duration Promoted price reductions (20\%-30\%) of target items on boards at entryway and on menu; 3 weeks

\begin{tabular}{l|l} 
Study design & Prospective measurement with a comparison group of nontarget items
\end{tabular}

Public awareness No information

Main outcome $\quad$ Sales data of target and nontarget items

measures

Effectiveness

Sales of target items increased by $357 \%$ on average compared with baseline; sales of nontarget comparison items remained constant

\section{POP + Availability + Promotion}

Scott et al, 1979 (41)

Setting, location, and 2 outlets, Houston, Texas, USA; urban area urbanicity

Activities and duration Created and labeled menu items low in cholesterol and saturated fat; promoted the program in the newspaper; 1 year

Study design $\quad$ Multiple postmeasures; no comparison group

Public awareness

Main outcome

measures

Effectiveness $\quad$ No significant change in sales over 12-month post intervention

Anderson and Hass, 1990 (47)

Setting, location, and 53 outlets, Colorado locations, USA, unknown urbanicity

urbanicity

Activities $^{b}$ and $\quad$ Created and labeled menu items low in calories, fat, cholesterol, and sodium; table tents provided information duration about the program and encouraged patrons to try labeled items; 4 weeks

Study design $\quad$ Multiple pre- and postmeasurements no comparison group

Public awareness

Main outcome measures

Effectiveness No information

Sales data

Abbreviation: POP, point of purchase.

a Interventions were grouped into categories according to their use of the following intervention strategies singly or combined: promotion and communication (Promotion), point-of-purchase information (POP), increased availability (Availability), reduced prices and coupons (Pricing), catering policies (Catering), and increased access (Access)(11).

${ }^{\mathrm{b}}$ This intervention clearly describes that individual restaurant owners had the flexibility to choose some or all of the strategies offered. Thus, the intervention category reflects the range of activities carried out by the intervention. 
(continued)

Table 3. Studies Published from 1979 Through January 2014 on Community-Based Restaurant Interventions ( $\mathrm{n}=27$ ) to Promote Healthy Eating, by Categorya

\begin{tabular}{|c|c|}
\hline $\begin{array}{l}\text { Intervention } \\
\text { Category }^{\mathrm{a}}\end{array}$ & Summary Data \\
\hline Effectiveness & $\begin{array}{l}52 \text { out of the } 58 \text { target items had an increase in sales, but no information about the magnitude of the increase } \\
\text { in sales was provided }\end{array}$ \\
\hline \multicolumn{2}{|c|}{ Fitzpatrick et al, 1997 (48) } \\
\hline $\begin{array}{l}\text { Setting, location, and } \\
\text { urbanicity }\end{array}$ & 9 outlets, Vancouver, British Columbia, Canada; urban area \\
\hline Activities and duration & $\begin{array}{l}\text { Created and labeled menu items with reduced fat and smaller portion sizes; promoted through local media, } \\
\text { table tents, menu inserts, and window decals; } 4 \text { weeks }\end{array}$ \\
\hline Study design & Single postmeasurement; comparison group of regular items \\
\hline Public awareness & No information \\
\hline $\begin{array}{l}\text { Main outcome } \\
\text { measures }\end{array}$ & Satisfaction with reduced-fat foods compared with regular items \\
\hline Effectiveness & $\begin{array}{l}\text { Overall customer satisfaction was higher when served lower-fat item (rated } 4.5 \text { out of } 5) \text {, compared with } \\
\text { satisfaction with a regular item ( } 4.28 \text { out of } 5) \text {, resulting in a } 5.1 \% \text { difference }\end{array}$ \\
\hline \multicolumn{2}{|l|}{ Richard et al, 1999 (33) } \\
\hline $\begin{array}{l}\text { Setting, location, and } \\
\text { urbanicity }\end{array}$ & 2 outlets, St. Henri, Montreal, Quebec, Canada; urban area \\
\hline $\begin{array}{l}\text { Activities }{ }^{b} \text { and } \\
\text { duration }\end{array}$ & $\begin{array}{l}\text { Created and labeled menu items; expanded menu to include lowfat milk and dressing, and whole wheat bread; } \\
\text { promoted the program with posters, placemats, newspapers, and leaflets; } 19 \text { weeks }\end{array}$ \\
\hline Study design & Single postmeasurement; no comparison group \\
\hline Public awareness & Average awareness of the program was $23.6 \%$ \\
\hline $\begin{array}{l}\text { Main outcome } \\
\text { measures }\end{array}$ & Reported behaviors \\
\hline Effectiveness & $\begin{array}{l}\text { On average, } 53.4 \% \text { of surveyed patrons ordered targeted entrées; specifically, } 77.1 \% \text { in family style restaurant } \\
\text { and } 18 \% \text { in fast-food restaurant ordered targeted entrée }\end{array}$ \\
\hline \multicolumn{2}{|l|}{ Blair et al, 2011 (39) } \\
\hline $\begin{array}{l}\text { Setting, location, and } \\
\text { urbanicity }\end{array}$ & 6 outlets, Frederick County, Massachusetts USA; urban area \\
\hline $\begin{array}{l}\text { Activities }{ }^{b} \text { and } \\
\text { duration }\end{array}$ & $\begin{array}{l}\text { Created and labeled menu items for a diabetes awareness month challenge; promoted challenge through table } \\
\text { tents, flyers, newspapers, and radio stations; } 4 \text { weeks }\end{array}$ \\
\hline Study design & Design not suitable to evaluate effectiveness \\
\hline Public awareness & No information \\
\hline $\begin{array}{l}\text { Main outcome } \\
\text { measures }\end{array}$ & General response from patrons and restaurant staff \\
\hline Effectiveness & No information \\
\hline & POP + Promotion + Pricing \\
\hline
\end{tabular}

Abbreviation: POP, point of purchase.

a Interventions were grouped into categories according to their use of the following intervention strategies singly or combined: promotion and communication (Promotion), point-of-purchase information (POP), increased availability (Availability), reduced prices and coupons (Pricing), catering policies (Catering), and increased access (Access)(11).

$\mathrm{b}$ This intervention clearly describes that individual restaurant owners had the flexibility to choose some or all of the strategies offered. Thus, the intervention category reflects the range of activities carried out by the intervention. 
(continued)

Table 3. Studies Published from 1979 Through January 2014 on Community-Based Restaurant Interventions ( $\mathrm{n}=27$ ) to Promote Healthy Eating, by Categorya

\begin{tabular}{|l|l|}
$\begin{array}{l}\text { Intervention } \\
\text { Category }\end{array}$ & \multicolumn{2}{|l}{} \\
\hline Lefebvre, 1986 (49) & \multicolumn{2}{|l}{$\begin{array}{l}\text { Setting, location, and } \\
\text { urbanicity }\end{array}$} & 26 outlets, Pawtucket, Rhode Island; urban area \\
\hline $\begin{array}{l}\text { Activities } \\
\text { duration }\end{array}$ & $\begin{array}{l}\text { Labeled existing healthy menu items; promoted } \\
\text { in newspapers and in the Guide to Healthy Eatin } \\
\text { 3.77 years }\end{array}$ \\
\hline Study design & Design not suitable to evaluate effectiveness \\
\hline Public awareness & No information \\
\hline $\begin{array}{l}\text { Main outcome } \\
\text { measures }\end{array}$ & Restaurant owners' response to the program \\
\hline Effectiveness & No information \\
\hline
\end{tabular}

Horgen and Brownell, 2002 (17)

Setting, location, and 1 outlet, Huntsville, Alabama; urban area urbanicity

Summary Data

Activities and duration Identified a list of healthy options with health messages (gain-framed and loss-framed); promoted price reductions (20\%-30\%) of target items on boards at entryway and on menu; 2 weeks

\begin{tabular}{l|l} 
Study Design & Prospective measurement with a comparison group of nontarget items
\end{tabular}

Public awareness

\begin{tabular}{l|l} 
Main outcome & Sales data of target and nontarget items
\end{tabular}

measures

Effectiveness

Sales of target items increased by $326 \%$ on average compared with baseline; sales of nontarget comparison items remained constant

Promotion + Availability + Pricing

Acharya et al, 2006 (20)

Setting, location and 9 or more outlets, Greater San Diego Area, California; urban area urbanicity

Activities and duration Created and promoted healthy menu items through table tents, posters, community events, and ads in magazines, newspaper, and television; distributed coupons; 1 year

\begin{tabular}{l|l} 
Study design & Prospective measures with a comparison group of restaurants
\end{tabular}

Public awareness $\quad 11.5 \%$ of patrons surveyed were aware of the Treat Yourself Well program

\begin{tabular}{l|l} 
Main outcome & Beliefs and attitudes toward healthy options and reported purchase of a healthy menu item
\end{tabular}

measures

Effectiveness

The intervention survey respondents were $3.7 \%$ more likely to purchase the healthy menu items than the control group; coupon-holders were $17 \%$ more likely to purchase a healthy item

\section{POP + Availability + Promotion + Pricing}

Abbreviation: POP, point of purchase.

a Interventions were grouped into categories according to their use of the following intervention strategies singly or combined: promotion and communication (Promotion), point-of-purchase information (POP), increased availability (Availability), reduced prices and coupons (Pricing), catering policies (Catering), and increased access (Access)(11).

${ }^{\mathrm{b}}$ This intervention clearly describes that individual restaurant owners had the flexibility to choose some or all of the strategies offered. Thus, the intervention category reflects the range of activities carried out by the intervention. 
(continued)

Table 3. Studies Published from 1979 Through January 2014 on Community-Based Restaurant Interventions ( $\mathrm{n}=27$ ) to Promote Healthy Eating, by Categorya

\begin{tabular}{|c|c|}
\hline $\begin{array}{l}\text { Intervention } \\
\text { Category }^{\mathrm{a}}\end{array}$ & Summary Data \\
\hline \multicolumn{2}{|c|}{ Economos et al, 2009 (50) } \\
\hline $\begin{array}{l}\text { Setting, location, and } \\
\text { urbanicity }\end{array}$ & 21 outlets, Somerville, Massachusetts; urban area \\
\hline $\begin{array}{l}\text { Activities }{ }^{b} \text { and } \\
\text { duration }\end{array}$ & $\begin{array}{l}\text { Created and labeled menu items; promoted through table tents, menu inserts, signs, and newsletters; provided } \\
\text { coupons; } 1.62 \text { years }\end{array}$ \\
\hline Study design & Design not suitable to evaluate effectiveness \\
\hline Public awareness & No information \\
\hline $\begin{array}{l}\text { Main outcome } \\
\text { measures }\end{array}$ & Restaurant owners' use of materials and thoughts about the program \\
\hline Effectiveness & No information \\
\hline \multicolumn{2}{|l|}{ Hanni et al, 2009 (22) } \\
\hline $\begin{array}{l}\text { Setting, location, and } \\
\text { urbanicity }\end{array}$ & 16 or more outlets, Salinas, CA; urban area \\
\hline Activities and duration & $\begin{array}{l}\text { Created and labeled menu items; promoted through newspaper ads and brochures about diabetes risk } \\
\text { assessment; coupons were provided; } 5 \text { years }\end{array}$ \\
\hline Study design & Design not suitable to evaluate effectiveness \\
\hline Public awareness & No information \\
\hline $\begin{array}{l}\text { Main outcome } \\
\text { measures }\end{array}$ & Restaurant owners' use of materials and thoughts about the program \\
\hline Effectiveness & No information \\
\hline
\end{tabular}

Abbreviation: POP, point of purchase.

a Interventions were grouped into categories according to their use of the following intervention strategies singly or combined: promotion and communication (Promotion), point-of-purchase information (POP), increased availability (Availability), reduced prices and coupons (Pricing), catering policies (Catering), and increased access (Access)(11).

${ }^{b}$ This intervention clearly describes that individual restaurant owners had the flexibility to choose some or all of the strategies offered. Thus, the intervention category reflects the range of activities carried out by the intervention. 